\title{
Does broadband speed really matter for driving economic growth? Investigating OECD countries ${ }^{1}$
}

\author{
Ibrahim Kholilul Rohman, Erik Bohlin \\ Division of Technology and Society, \\ Department of Technology Management and Economics \\ Chalmers University of Technology, Gothenburg, Sweden \\ Ibrahim.rohman@chalmers.se
}

\begin{abstract}
This paper aims to measure the impact of broadband speed on economic growth in the OECD countries. The macroeconomic indicators for this study were collected from OECD databases, except for the speed data, which were gathered from Ookla, a company that provides broadband testing and web-based network diagnostic applications data on a daily basis. With this, quarterly balanced panel data for 34 OECD countries during the period 2008-2010 were examined. The study found that the estimated coefficient of broadband speed is statistically significant. Doubling the broadband speed will contribute to $0.3 \%$ growth compared with the growth rate in the base year. The results convey that the impact of increasing broadband speed on GDP growth will largely depend on two aspects: (i) the size of the coefficient of the broadband speed (beta) and (ii) the existing economic growth in each country. Consequently, since the coefficient is linear, the impact will also be relatively greater for countries that experienced lower economic growth during previous years. Finally, the paper provides suggestions for future research in this vein and further calibration of future models.
\end{abstract}

Keywords: broadband, speed, economic growth, OECD, panel data, fixed effect, advertised speed, measured speed

\section{Introduction}

The importance of broadband development is tightly linked to technology in general, as broadband is also a catalyst for other sectors to grow as part of so-called General Purpose Technology (GPT). Therefore, by investing in wireless broadband access infrastructure, jobs and income are created not only by direct investment, which creates or expands existing network capacity, speed and reliability, but also through the indirect benefits of filling coverage holes and providing wireless broadband services. The widespread availability and adoption of high-speed broadband Internet access by consumers is a key driver of information and communication technology (ICT) capabilities and the overall prosperity and wellbeing of the economy of a developed nation (Marcus, 2005).

\footnotetext{
${ }^{1}$ This study has been conducted in collaboration with LM Ericsson AB and Arthur D. Little AB. We are grateful to the Consumer Lab of LM Ericsson AB for data support, and to Erik Almqvist, Johan Dahlborg and Andreas Gjelstrup of Arthur D. Little $A B$, for discussions and advice. The authors are responsible for all remaining errors.
} 
The resulting improvement in wireless broadband access creates new business based on the availability of faster Internet connections. As Lennett and Meinrath (2009) mentioned, the broadband and telecommunication infrastructures that facilitate high-speed connectivity can no longer be seen as a luxury but as critical. In the United States, Pearce and Pagano (2009) estimated that new wireless broadband investments of $\$ 17.4$ billion would increase the gross domestic product (GDP) within twenty-four months of making the additional investment by between $0.9 \%$ and $1.3 \%$, which, in dollar terms, translates to between $\$ 126.3$ billion and \$184.1 billion. Kolko (2010) also added that there is a positive relationship between broadband expansion and economic growth. This relationship is even stronger in industries with a great reliance on information technology and in areas with low population densities. As well as this, broadband will result in an increase of between 4.5 million and 6.3 million jobs, a huge margin from the early investigation of impact by Pociask (2002), which found that a nationwide network would expand employment in the United States by an estimated 1.2 million new and permanent jobs.

The contribution by broadband is also crucial and increasingly important in emerging countries. Lee and Lee (2003) reported that with the growing popularity of the Internet, Korea has been successful in providing broadband Internet services to the level of universal service. More than $70 \%$ of households have high-speed Internet connection, and people's lives had been changed dramatically by 2003. Moreover, Lee and Shim (2005) found that there is evidence of positive impacts of broadband development in Korea. Most importantly, broadband Internet not only provides a driving force for new businesses for related industries but also forms a springboard for future infrastructure in the network economy. Badran and Badran (2011) found the same results in Arab countries. Based on the investigation in 22 emerging countries in the region from 1998 to 2008 , the empirical study shows that there is a positive impact of broadband uptake on economic growth.

Supported by the need to estimate direct and indirect impacts when evaluating broadband, Katz (2009) summarizes existing literature investigating this issue, especially that which has adopted the Input-Output (IO) method. Katz distinguished that the direct impact relates to the jobs created from the deployment of the infrastructure (e.g. construction), while the indirect impact is generated by the network externalities from the other sectors of the economy. A summary of the studies is presented in Table 1. 
Table 1. The multiplier effect of broadband: previous studies ${ }^{2}$

\begin{tabular}{|l|l|l|l|}
\hline Author & Location & Type I & Type II \\
\hline Crandall et al. (2003) & United States & NA & 2.17 \\
\hline Atkinson et al. (2009) & United States & NA & 3.6 \\
\hline Katz et al. (2009b) & United States & 1.83 & 3.43 \\
& & & \\
\hline Liebenau et al. (2009) & United Kingdom & NA & 2.76 \\
\hline Katz et al. (2009c) & Germany & 1.45 & 1.93 \\
\hline
\end{tabular}

From the summary in Table 1, it can be concluded that previous studies found that the multiplier of broadband varies from 1.43 to 3.6 depending on the region being investigated and the type of multiplier. It indicates that every 1 euro spent on the final demand of the broadband product and services will increase economic output by 1.43-3.6 euro.

Having highlighted a large proportion of the studies that have been conducted to estimate the impact of broadband on the economy, few are devoted to investigating the impact of broadband speed on the economy. Stenberg and Morehar (2010) mentioned that via high-speed technology, such as DSL lines, cable, satellite and wireless networks, the Internet will be more useful to businesses, households and governments, and it will ignite an explosion in electronic commerce. In the case of Australia, Atapattu (2010) argued that high-speed broadband Internet access is also widely recognized as a catalyst for social and economic development. The inherent dispersed population of a large geographical area in rural Australia will benefit from the delivery of more efficient, well-maintained and cost-effective data transfers. In the other study, Howell and Grimes (2010) accentuated that fast Internet access is widely considered to be a productivity-enhancing factor, even though the productivity gains may not be as large as originally hypothesized.

With regard to the development of broadband in the OECD countries, Wallsten (2009) summarizes that household broadband adoption continues to increase quickly in this group of countries. Furthermore, the speeds also continue to increase with four OECD countries, Korea, Japan, Sweden and the Netherlands, at 18,15, 12 and 9.4 mbps respectively, having average download speeds well

2 Type I effects measure the impact as the ratio of the total of direct and indirect divided by direct (direct+indirect/direct) while the Type II effects estimate the impact as the ratio of the sum of direct, indirect and induced divided by direct (direct+indirect+induced/direct) ${ }^{2}$. Yan (1968, p.70) gives details that the induced effect is due to additional consumption from additional income. Thus, the 10 includes households in the production system. 
above those of others in the first quarter of 2009. Another 12 countries had average download speeds of between 6 and $8 \mathrm{mbps}$, including the United States with an average speed of $6.4 \mathrm{mbps}$.

Given the growing importance of the analysis of broadband speed to developed countries, this study aims to investigate the impact of broadband speed on economic growth in the OECD countries. The paper is presented in the following sections. Section 2 looks at the discussion on broadband speed, especially in relation to the measurement and source of the data. The descriptive analysis of the OECD economy is elaborated on in Section 3, and the methodology of the study is discussed in Section 4. The results are presented in Section 5. Section 6 concludes the study.

\section{Broadband speed}

As the Internet economy has evolved, more online applications have required higher data transmission rates. The low transmission capability and speed of dial-up Internet service severely limit access to content-dense applications and websites. As a result, broadband access has become a necessity for those wishing to benefit from the full economic potential of the Internet (Stenberg et al., 2009). The definition of broadband speed is an important aspect to be clearly identified as it has consequences when conducting the analysis, given the different measurements and definitions out there. The notion of broadband speed is commonly used in relation to the type of Internet connection. For instance, dial-up Internet connection has limited but predictable access capacity, normally not more than $56 \mathrm{kbit} / \mathrm{s}$. A broadband connection, however, is capable of always being on. Therefore, as best practice, data rates of $256 \mathrm{kbps}$ and above are considered broadband (OECD, 2009).

Besides this, there are generally two notations of speed data. The first is by measuring it and the second by conceiving it from the advertisement. The measured speed is calculated from the gross and net bits, whereas the advertised speed indicates the speed level offered by the provider as specified in the contract/advertisement. Ideally, when analysing the effects of broadband speed, the measured speed is preferable to the advertised speed as the latter does not always correspond to the real speed experienced by the user. Apart from this, the advertised speeds may differ substantially from those measured, as shown in Fig. 1. 


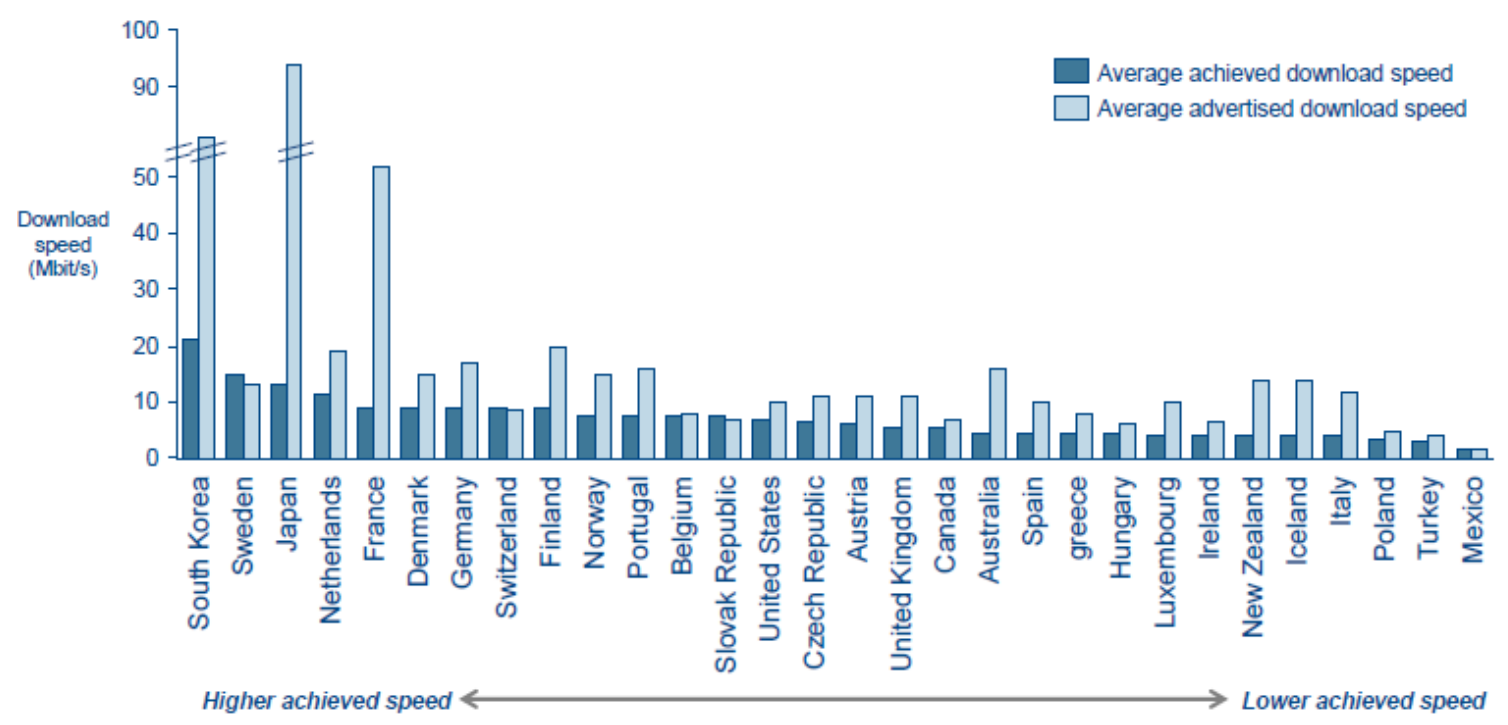

Source: Arthur D. Little (ADL) (2011)

Fig. 1. Comparison between advertised speed and measured speed

It can be concluded from Fig. 1 that the gap between the speed measurements may vary between countries and, in most cases, the advertised speed is higher than the actual speed. Surprisingly, based on the figures, only Sweden has a higher actual speed than advertised speed and, for other countries, the figures are the opposite.

Another issue when evaluating the speed impact is the fact that each data source shows different outcomes for the speed level, as shown in Fig. 2.
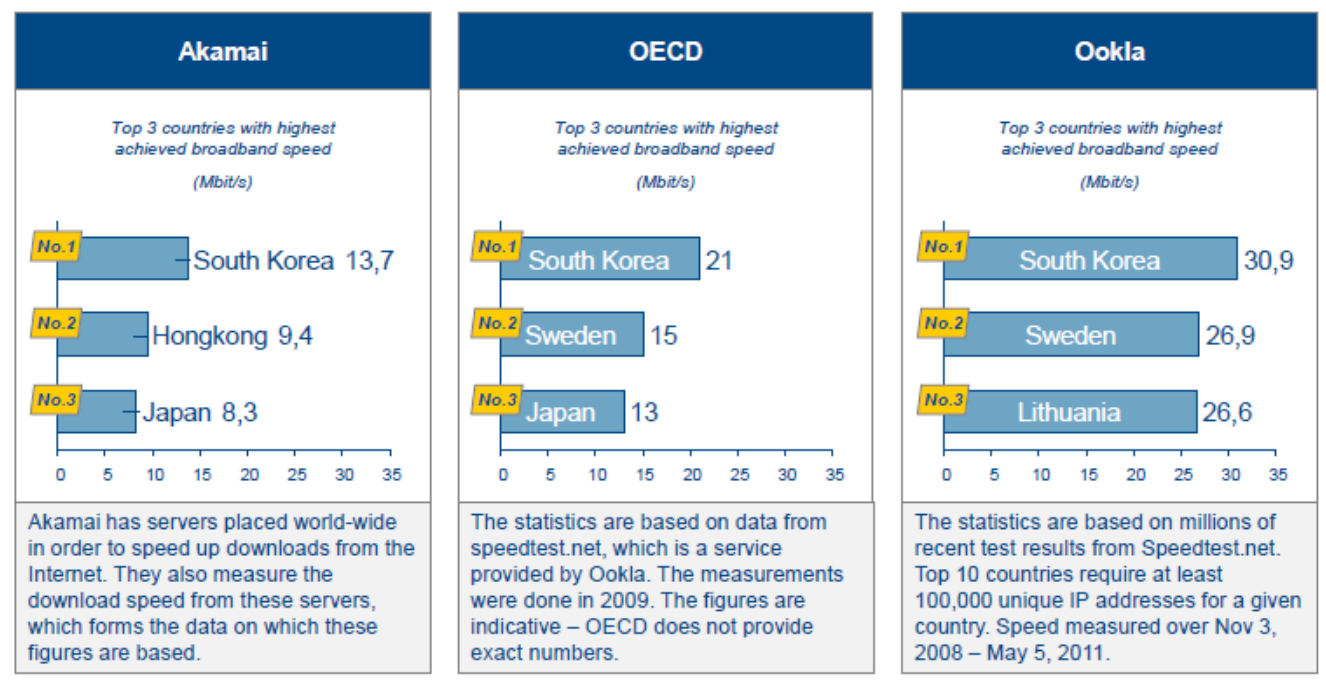

Source: ADL (2011)

Fig. 2. Speed level from different data sources 
Fig. 2 tells us that while the rank of the speed level only varies slightly, the speed of data differs significantly between countries. Knowing the difference in the data generated from different sources, as shown in Fig. 2, this study therefore consistently employs the speed data from Ookla. The company is one of the global leaders in broadband testing and web-based network diagnostic applications with certain standards for accuracy, popularity, ease of use and subsequent development of statistical data, given the fact that more than three million people a day use the software. The test sites include Speedtest.net, Pingtest.net and Net Index. The data from Ookla include mobile and fixed broadband speeds as a blended figure in the daily base data.

\section{OECD Economy}

The following section briefly presents the characteristics of the broadband economy in the OECD countries. The Organization for Economic Co-operation and Development (OECD) was founded in 1961 with the main aim of stimulating economic progress and trade. Currently, the organization has 34 countries as members on 4 continents in the world. Fig. 3 presents the average economic growth of the countries.

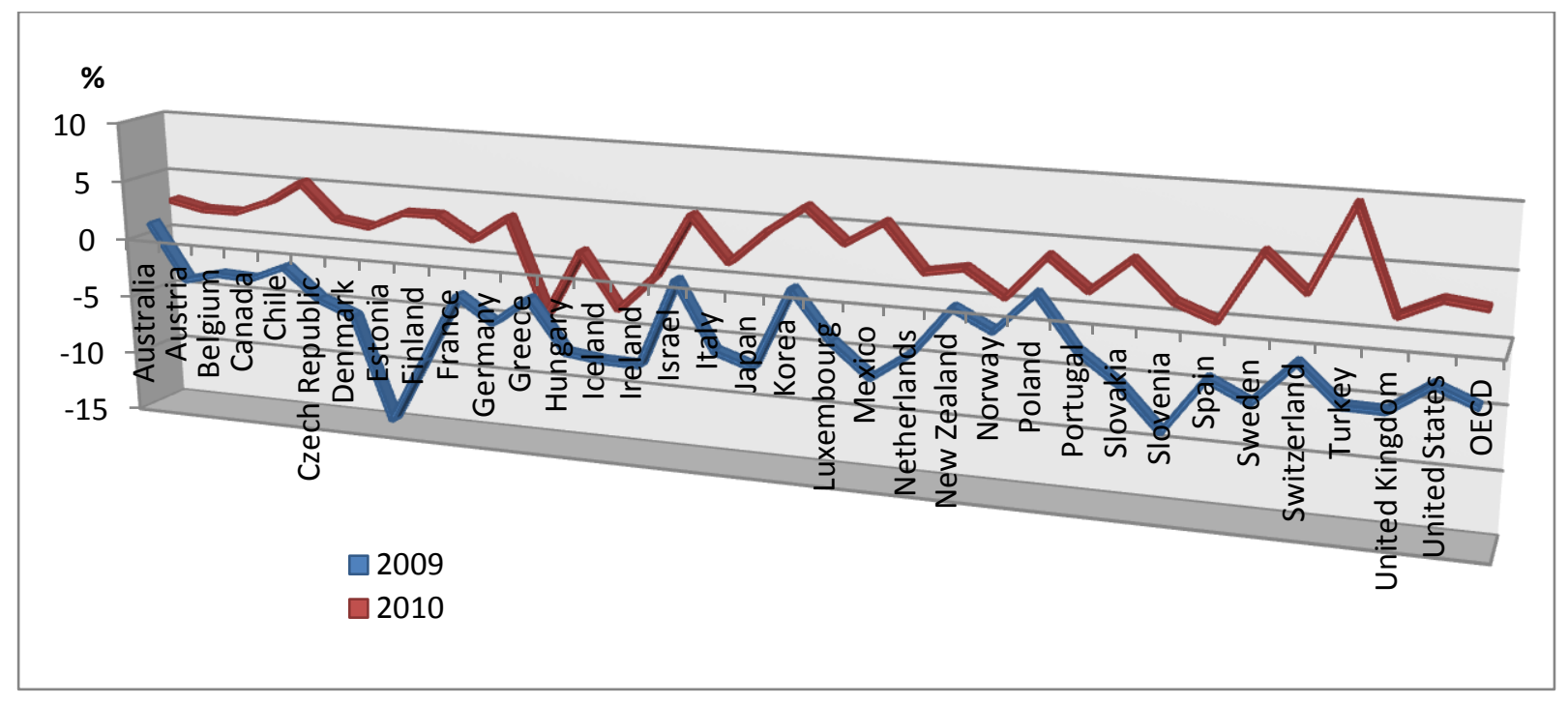

Fig. 3. Average growth of GDP from 2009 to 2010 (as a percentage)

Fig. 3 shows the average growth of GDP for the OECD countries in 2009 and 2010. Overall, the GDP growth gradually increased for all countries in 2010. However, compared with 2009, some countries grew rapidly while others declined in 2010. The first 6 countries that had positive growth and increased rapidly in 2010 were Estonia, Turkey, Mexico, Finland, Sweden and Japan. The GDP growth for Estonia increased by an average of $17 \%$ while Turkey was at $14 \%$. Mexico, Finland, Sweden and Japan increased by $12 \%, 11 \%, 11 \%$ and $10 \%$ respectively. The GDP growth for Greece, however, has 
declined by about $2 \%$ and will be even worse as the current crisis hits the European region, particularly in the south.

Fig. 4 describes the progress of the broadband penetration rate.

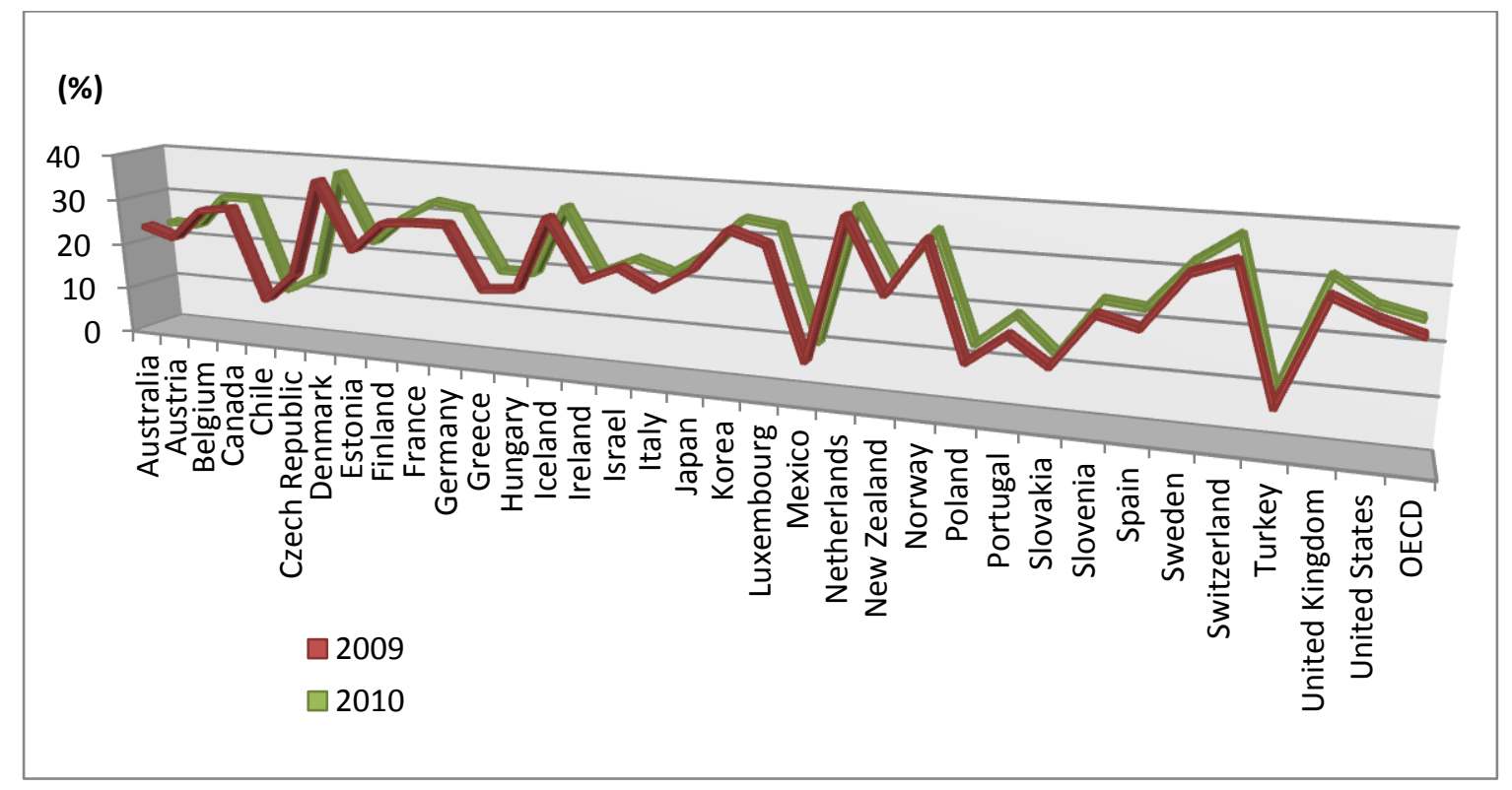

Fig. 4. Average fixed broadband penetration rate from 2009 to 2010 (as a percentage)

Fig. 4 shows the average fixed broadband penetration rate for the OECD countries in 2009 and 2010. The penetration rates are almost the same for all the OECD countries for 2009 and 2010 . The countries that have the highest fixed broadband penetration rate in 2010 are the Netherlands, Denmark, Switzerland, Norway, Korea and Iceland. The average fixed broadband penetration rate for the Netherlands is $38 \%$ while that for Iceland is $33 \%$. The countries that had the lowest penetration rate in 2010 were Chile, Mexico and Turkey with penetration rates of 10\%, 10\% and 9\% respectively. 


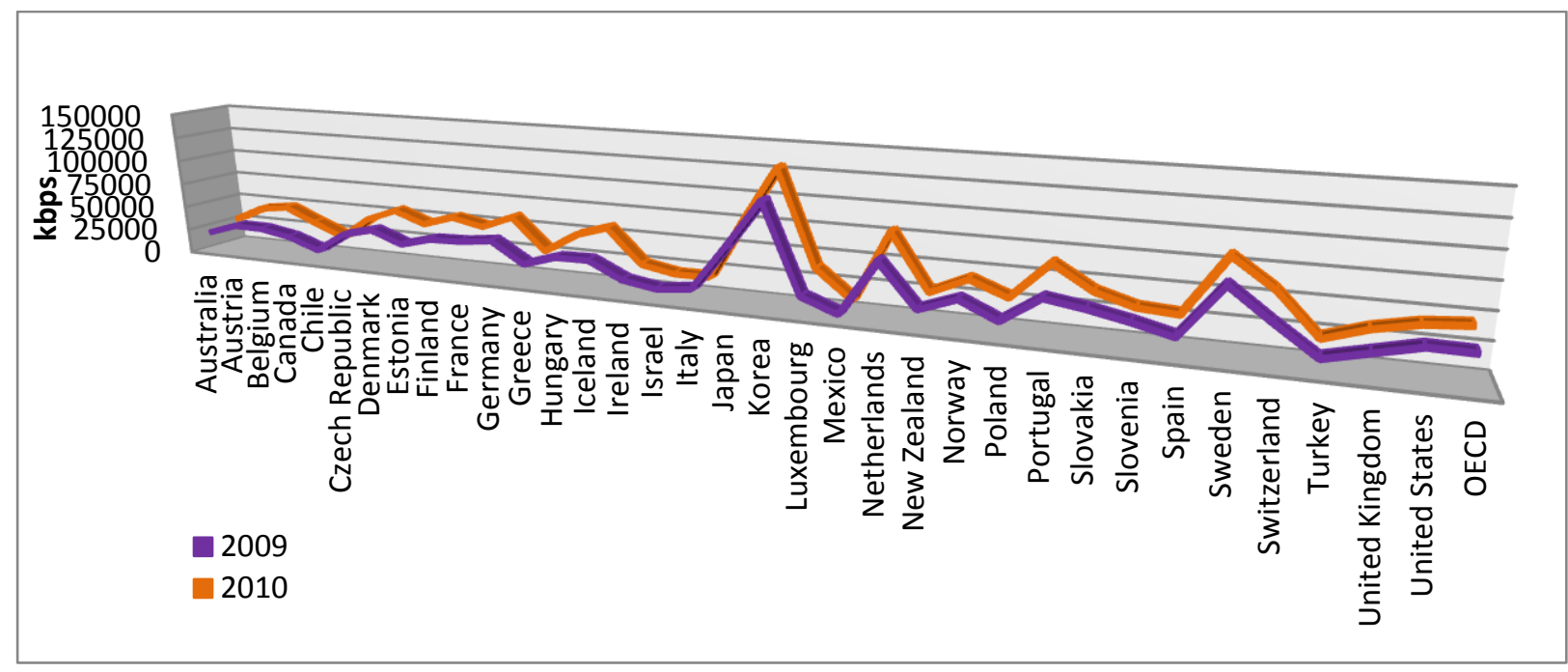

Fig. 5. Average download speeds from 2009 to 2010 (in kbps)

Fig. 5 shows the average download speeds for the OECD countries in 2009 and 2010. Compared with 2009, the download speed for all the countries increased in 2010. Korea has the highest download speed of the OECD countries. Sweden has the second highest, followed by the Netherlands and Japan. In terms of growth, the download speed for Luxembourg in 2010 increased to $84 \%$ while that of Iceland increased to $70 \%$ compared with 2009. Poland, Belgium and Portugal increased their download speeds to $61 \%, 51 \%$ and $51 \%$ respectively in 2010 .

\section{Methodology}

Given the limited empirical studies measuring the impact of broadband speed on the economy, this paper adopts previous studies that measure the impact of the broadband penetration rate on the economy with some more adjustments to allow the speed impact to be captured. The main methodology of the econometrics model is derived from Lehr et al. (2005) and employs national and zip code data to estimate the impact of broadband in the United States. The study concluded that broadband access enhances economic growth and performance, and that the economic impact of broadband is real and measurable in the United States. The study describes that during the period 1998-2002, communities in which mass-market broadband became available by December 1999 experienced more rapid growth in employment, number of businesses overall and businesses in ITintensive sectors.

The theoretical model in the study is derived as follows. The growth rate of GDP in relation to the growth in the base year is depicted in the following relationship: 
$\operatorname{Ln}[Y(t)]=A \propto \operatorname{Ln}[Y(0)] . r$

where $\mathrm{Y}$ is the GDP per capita, $\operatorname{Ln} a=A$ and $\operatorname{Ln}[X \beta+\gamma B B+\varepsilon]=r=r^{*}+\gamma B B+X \beta+\varepsilon$. BB is the variable corresponding to the broadband penetration rate and $X$ is the other control variables.

By taking the exponential,

$Y(t)=A \propto e^{L n[Y(0)]} e^{r}$

at interval $[0, \mathrm{t}]$,

$Y(t)=A Y(0)^{\propto} e^{r t}$

If $r$ is viewed as the growth rate, then $A=1$ and $\alpha=1$, and

$Y(t)=Y(0) e^{r *+\gamma B B+X \beta+\varepsilon}$

$\frac{Y(t)}{Y(0)}=e^{r *+\gamma B B+X \beta+\varepsilon}$

$\ln \left(\frac{Y(t)}{Y(0)}\right)=r^{*}+X \beta+\gamma B B+\varepsilon$

Assuming that $a=r^{*}$, then

$\ln \left(\frac{Y(t)}{Y(0)}\right)=a+X \beta+\gamma B B+\varepsilon$

$g(t)=a+X \beta+\gamma B B+\varepsilon$

Eq. (8) is the model to examine the impact of broadband speed, putting the relative growth of GDP as the dependent variable. While Lehr et al. (2005) did not estimate the impact of broadband speed and instead only the impact of the broadband penetration rate on GDP, this research adopts a similar model, replacing the broadband penetration rate data with broadband speed using two stages of the fixed effect panel model to avoid the endogeneity problem of speed data.

The first stage of the analysis is to estimate the broadband speed as a function of some independent variables.

broadband speed $_{i t}=\alpha_{0}+\alpha_{1} \quad$ penetration rate pit $\quad+\alpha_{2} \quad$ price $_{i t}+\alpha_{3}$ urban population $_{i t}+$ $\alpha_{4}$ density $_{i t}+\alpha_{5}$ telecom revenue $_{i t}$

The second stage is another expression of Eq. (8) that is also the main equation to be estimated in this study. 
GDPcap $_{\text {it }}{/ \text { GDPCap }_{\text {ibase }}}=\alpha_{0}+\alpha_{1}$ average growt $_{i}+\alpha_{2}$ broadband speed $_{i t}+$

$\alpha_{j}$ other control variables $i t$

Equations (9) and (10) are both in log form, thus the coefficients reflect the elasticity with respect to the GDP growth. The control variables in Eq. (9) - the broadband speed equation - are broadband penetration rate, broadband subscription price, urban density, proportion of the urban population and telecom revenue, whereas the control variables in Eq. (10) - the main equation - are urban density, proportion of the urban population, labour force, proportion of tertiary education and population.

Eq. (9) is estimated in the first stage to avoid the endogeneity problem, having said that the speed level is tightly related to the stage of broadband development. It is also conceived that the broadband speed of the country is related to the demand and supply sides of broadband development. The demand side consists of the penetration rate, price, urban population and density whereas the supply side concerns the ability of the industry to provide the infrastructure (proxied by telecom revenue). This framework has also been used when analysing economic changes due to changes in ICT infrastructure, for example, Koutroumpis (2009).

With regard to the econometric modelling, the study also employs panel data regression, which has some advantages, especially to control individual heterogeneity and present more informative data that are unobserved in the cross-section econometrics testing. The structure of the panel data can be presented as follows:

$Y_{i t}=X_{i t} \beta+Z_{i} \alpha+\varepsilon_{i t}$

$Y_{i t}$ is the dependent variables, with a matrix size of (NT $\left.x i\right), X_{i}$ is the k-regressors of the exogenous variables, not including the constant (NT $x k$ ), $\beta$ is the parameter ( $k \times 1), Z_{i} \alpha$ is the heterogeneity or individual effect $i$, which consists of constant i. $\varepsilon_{i t}$ is the error term (NT $\times 1$ ), i is a cross-section member (individual) and $\mathrm{t}$ is time.

\section{Results}

Fig. 6 shows the descriptive statistical relationship between broadband speed and GDP per capita in terms of the correlation between the two variables. 

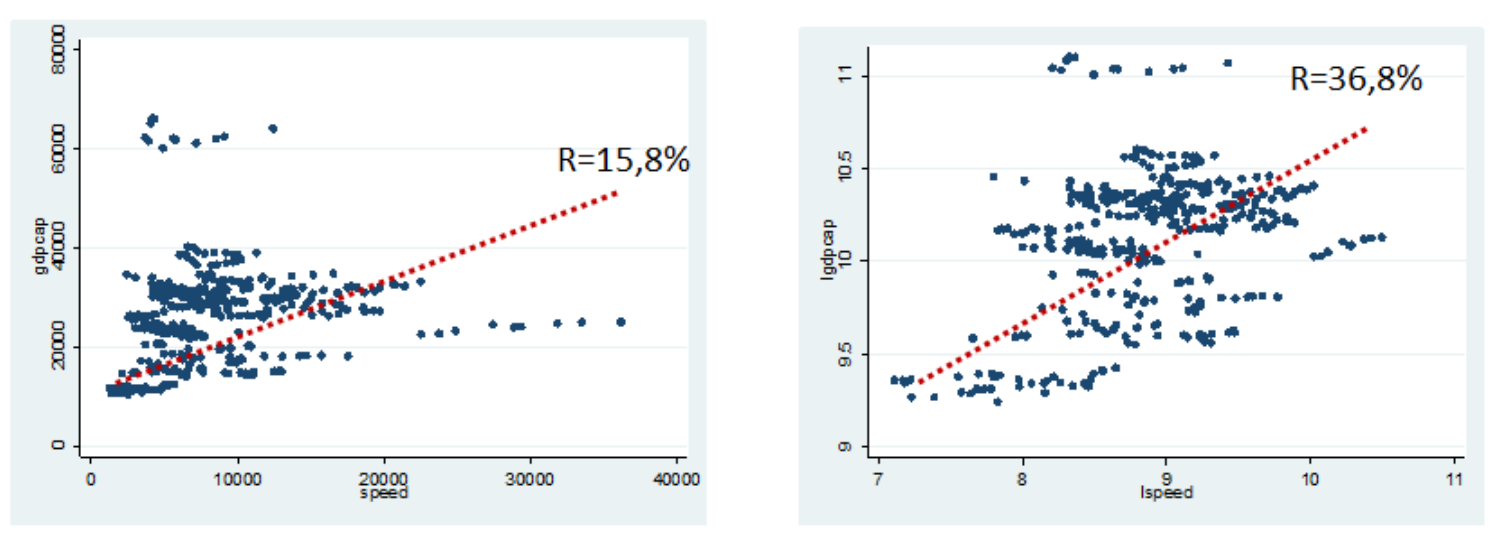

Fig. 6. The relationship between speed and GDP per capita (left-hand side level, right-hand side growth)

Fig. 6 shows that there is a positive correlation between the speed of broadband and the GDP per capita. The coefficient of the correlation is even greater when the data are measured at growth level (when the variable is measured at the log instead of the actual value).

Furthermore, the econometrics testing employing the two-step analysis of fixed effect panel data based on Eqs. (9) and (10) finds the results shown in Table 2.

Table 2. The impact of broadband speed on the GDP per capita

\begin{tabular}{|l|l|l|}
\hline Independent variables & \multicolumn{2}{|c|}{ Coefficient } \\
\hline Average GDP growth (2008-2010) & 0.577 & $*$ \\
\hline Population density & -0.0441 & $*$ \\
\hline Urban population & -0.0103 & $* *$ \\
\hline Labour force growth (\%) & 0.483 & $*$ \\
\hline Telecom revenue growth (\%) & 0.0492 & $*$ \\
\hline Population growth (\%) & -0.630 & $* *$ \\
\hline Average achieved downlink speed & -0.00214 & \\
\hline Average achieved downlink speed squared & 0.00142 & $*$ \\
\hline
\end{tabular}

From the estimation, the Hausman test confirms the fixed effects regression as the best model (compared with the random effect), whereas the Durbin-Wu-Hausman (DWH) test confirms the successful isolation of the independent impact of speed on GDP and, hence, no endogeneity problem remains from the estimation. While the point of interest of this study is the impact of broadband speed on GDP, other explanatory variables are also worth discussing. Generally speaking, these variables are consistent with the hypothesis. The coefficient of population density, which is negative for GDP growth, is somewhat surprising. This may be because, as Boulhol, de Serres, and Molnar 
(2008) found in the case of OECD, population density is a much weaker indicator of GDP than the other geographic variables and therefore does not have a strong link to the GDP per capita. The population and urban density are both negative, as is also supported by similar results in the study by Kolko (2010).

The growth in the labour force is positive for GDP growth, as the variable is part of the factor of production based on the Cobb-Douglas production function framework. Telecom revenue is also part of GDP and hence the positive relationship is self-explanatory. Negative population growth for GDP growth is also consistent with the study by Boulhol, de Serres and Molnar (2008).

The estimated coefficient of broadband speed is not statistically significant, but the square of the variable with the value of 0.0014 is. The coefficient can be translated into an elasticity measurement, with elasticity values evaluated at the sample mean. Such an elasticity measurement is of the form: $2 *$ coefficient $=2 * 0.00142 \%=0.00284 \% \approx 0.003 \%$ additional GDP mean growth from the base year (2008) by a $1 \%$ increase in the speed level. The size of the coefficient is more readily understood in the context of a doubling of the average speed, that is, an increase of $100 \%$. The sample mean is 8.3 mbps, hence $16.6 \mathrm{mbps}$ for a $100 \%$ increase. If the speed level is doubled, the impact on GDP growth is $100 * 0.003=0.3 \%$ (relative to the growth in 2008). As an example, if the overall economic growth in 2008 is $2 \%$, then the hypothetical isolated impact from doubling the speed level on growth would be $2 \%+0.3 \%=2.3 \%$. Note, however, that the doubling of speed is a hypothetical and simulated ('what-if') impact based on an elasticity interpretation of the significant broadband speed variable. The hypothetical impact will depend on the size of the coefficient of speed and the actual economic growth in each country, counting from the base year that is used.

\section{Conclusion}

Broadband has played an important role for the economy, especially in the developed nations. Given the gap, the majority of academic studies on broadband development is devoted to measuring the causality of broadband development in terms of the penetration rate and GDP growth. This paper aims to measure the impact of broadband speed on economic growth in the OECD countries. This study concludes that the hypothetical impact of broadband speed on economic growth is statistically significant and the size largely depends on two aspects: (i) the size of beta (coefficient of speed) and (ii) the existing economic growth in each country. As the impact is modelled as linear, it needs to be judiciously applied when hypothetical country growth is far away from the sample means. The 
hypothetical impact is based on an elasticity measurement and any forward-looking simulation should be applied with care.

Having identified the importance of high-speed broadband, this study recommends that the initiatives for next-generation telecommunications networks are even more crucial at a time when the labour market conditions are particularly weak as they can help preserve jobs and head off a potential burden on social safety nets. Bringing forward longer term aggregate spillover effects of broadband can improve the productivity of the entire economy and is consistent with enhancing longer term growth and development (Qiang, 2010). Nevertheless, the policy should also consider the on-going trend that even before the recent financial crisis, there has been a dramatic downward trend in telecommunications investment (Cambini \& Jiang, 2009). For OECD countries, especially in the European region, the policy can be guided, particularly to give incentives to broadband suppliers to invest in network upgrades that extend service and improve quality and speed (Crandall et al., 2004). The policy should also aim to close the 'broadband gap' by supporting municipalities, local administrations, SMEs and other decision-makers in the development of broadband infrastructures (Lattemann et al., 2007).

\section{References}

Arthur D. Little (ADL). (2011). Socioeconomic effects of broadband speed. Research project, Stockholm: Arthur D. Little.

Atapattu, L. (2010). Channel tracking algorithms for highly efficient wireless broadband communications in rural areas. Proceedings of IEEE International Symposium on the World of Wireless Mobile and Multimedia Networks (WoWMoM) (pp.1-2). Retrieved from

http://ieeexplore.ieee.org/stamp/stamp.jsp?tp=\&arnumber=5534978\&isnumber=5534887

Atkinson, R. D., Castro, D. \& Ezell, S. J. (2009). The digital road to recovery: A stimulus plan to create jobs, boost productivity and revitalize America. Washington D.C.: The Information Technology and Innovation Foundation. Retrieved from www.itif.org/files/roadtorecovery.pdf

Badran, M. F. (2011). The impact of broadband infrastructure on economic growth in some emerging countries. Proceedings of the 10th international conference for the Middle East Economic Association (pp. 1-31). Barcelona, Spain. Retrieved from http://meeaweb.org/meea10/papers/badran.pdf

Boulhol, H., de Serres, A. \& Molnar, M. (2008). The contribution of economic geography to GDP per capita. OECD Journal: Economic Studies, 2008, 1-37.

Cambini, C. \& Jiang, Y. (2009). Broadband investment and regulation: A literature review. Telecommunications Policy, 33(10-11), pp. 559-574. 
Crandall, R. W., Jackson, C. L. \& Singer, H. J. (2003). The effect of ubiquitous broadband adoption on investment, jobs and the US economy. Washington, D.C.: Criterion Economics, L.L.C.

Crandall, R. W., Hahn, R. W., Litan, R. E. \& Wallsten, S. (2004). Bandwidth for the people. Policy Review, No. 127, October-November 2004. AEI-Brookings Joint Center Regulatory Analysis 04-01. Retrieved from http://ssrn.com/abstract=728569

Howell, B. \& Grimes, A. (2010). Productivity questions for public sector fast fiber network financiers. Communications \& Strategies, 78, pp. 127-145.

Katz, R. (2009). Estimating broadband demand and its economic impact in Latin America. Proceedings of the 3rd ACORN-REDECOM Conference. Mexico City. Retrieved from http://unpan1.un.org/intradoc/groups/public/documents/gaid/unpan036761.pdf

Katz, R. 'Estimating Broadband Demand and its Economic Impact in Latin America.' Proceedings of the 3rd ACORN-REDECOM Conference. Mexico City, 2009a.

Katz, R. \& Suter, S. Estimating the Economic Impact of the Broadband Stimulus Plan. Working Paper, Columbia Institute for Tele-Information, 2009b.

Katz, R., Waterlaus, S., Zenhäusern, P. \& Suter, S. The Impact of Broadband on Jobs and the German Economy. Working Paper, Columbia Institute for Tele-Information 2009c.

Kolko, J. (2010). Does broadband boost local economic development? [Report]. Retrieved from http://www.distributedworkplace.com/DW/Research/Does\%20Broadband\%20Boost\%20Local\%20Ec onomic\%20Development.pdf

Koutroumpis, P. (2009). The economic impact of broadband on growth: A simultaneous approach. Telecommunications Policy, 33(9), pp. 471-485.

Lattemann, C., Stieglitz, S., Kupke, S. \& Schneider, A.-M. (2009). Impact of PPPs to broadband diffusion in Europe. Transforming Government: People, Process and Policy, 3(4), pp.355-374.

Lee, Y.-K. \& Dongmyun Lee, D. (2003). Broadband access in Korea: Experience and future perspective. IEEE Communications Magazine, 41(12), pp. 30-36.

Lee, H., Oh, S. \& Shim, Y. (2005). Do we need broadband? Impacts of broadband in Korea. Info, 7(4), pp. 47-56.

Lehr, W. H., Osorio, C. A., Gillett, S. E. \& Sirbu, M. A. (2005). Measuring broadband's economic impact. Broadband Properties, paper 457, pp. 12-24. Retrieved from http://repository.cmu.edu/tepper/457

Lennett, B. \& Meinrath, S. (2009). Building a 21st century broadband superhighway - A concrete build-out plan to bring high-speed fiber connections to every community. Retrieved from http://www.policyarchive.org/handle/10207/bitstreams/15054.pdf

Liebenau, J., Atkinson, R., Kärrberg, P., Castro, D. \& Ezell, S. (2009). The UK's Digital Road to Recovery. London: LSE Enterprise LTD and Information Technology and Innovation Foundation, 2009. 
Marcus, J. S. (2005). Broadband adoption in Europe. IEEE Communications Magazine, 43(4), pp. 1820.

OECD. (2009). Working party on communication infrastructures and services policy - Indicators of broadband coverage [Report]. Retrieved from http://www.oecd.org/dataoecd/41/39/44381795.pdf

Ookla. http://www.ookla.com/January 3, 2012 (accessed May 14, 2011).

Pearce, A. \& Pagano, M. S. (2009). Accelerated wireless broadband infrastructure deployment: The impact on GDP and employment. Media, Law and Policy Journal, 18 (Spring 2009), pp. 11-34.

Pociask, S. B. (2002). Building a nationwide broadband network: Speeding job growth [Report]. Retrieved from http://lus.org/uploads/BuildingaNationwideBroadbandNetwork.pdf

Qiang, C. Z.-W. (2010). Broadband infrastructure investment in stimulus packages: Relevance for developing countries. Info, 12(2), pp. 41-56.

Stenberg, P. \& Morehar, M. (2010). Farm businesses, the digital economy, and high-speed access to the Internet. Delhi Business Review, 11(2), pp. 90-102.

Stenberg, P., Morehart, M. \& Cromartie, J. (2009). Broadband Internet service helping create a rural digital economy. Amber Waves, 7(3), pp. 22-26.

Wallsten, S. (2009). Understanding international broadband comparisons, 2009 update. Technology Policy Institute, Washington, DC. Retrieved from

http://www.techpolicyinstitute.org/files/understanding\%20international\%20broadband\%20compari sons\%202009\%20update\%207-9.pdf 
